\title{
Automated characterisation of intergrowth textures in mineral particles. A case study
}

\author{
L. Pérez-Barnuevo ${ }^{\mathrm{a}, *}$, E. Pirard ${ }^{\mathrm{b}}$, R. Castroviejo ${ }^{\mathrm{a}}$ \\ ${ }^{a}$ Universidad Politécnica de Madrid, Dpto. de Ingeniería Geológica, C/Rios Rosas, 21, 28003 Madrid, Spain \\ ${ }^{\mathrm{b}}$ Université de Liège, GeMMe, Georesources and Geo-imaging Lab Sart Tilman B52, 4000 Liège, Belgium
}

\begin{abstract}
A B S T R A C T
The characterisation of mineral texture has been a major concern for process mineralogists, as liberation characteristics of the ores are intimately related to the mineralogical texture. While a great effort has been done to automatically characterise texture in unbroken ores, the characterisation of textural attributes in mineral particles is usually descriptive. However, the quantitative characterisation of texture in mineral particles is essential to improve and predict the performance of minerallurgical processes (i.e. all the processes involved in the liberation and separation of the mineral of interest) and to achieve a more accurate geometallurgical model.

Driven by this necessity of achieving a more complete characterisation of textural attributes in mineral particles, a methodology has been recently developed to automatically characterise the type of intergrowth between mineral phases within particles by means of digital image analysis. In this methodology, a set of minerallurgical indices has been developed to quantify different mineralogical features and to identify the intergrowth pattern by discriminant analysis. The paper shows the application of the methodology to the textural characterisation of chalcopyrite in the rougher concentrate of the Kansanshi copper mine (Zambia). In this sample, the variety of intergrowth patterns of chalcopyrite with the other minerals has been used to illustrate the methodology. The results obtained show that the method identifies the intergrowth type and provides quantitative information to achieve a complete and detailed mineralogical characterisation. Therefore, the use of this methodology as a routinely tool in automated mineralogy would contribute to a better understanding of the ore behaviour during liberation and separation processes.
\end{abstract}

\section{Introduction}

Texture is a critical mineralogical feature for the characterisation of ore behaviour during mineral processing. The possibility of achieving liberation by comminution, thus the potential recovery, is intimately related to textural relationships between minerals. However, texture characterisation is usually subjective (Bonici et al., 2008) and traditionally more related to ore deposit exploration than to mineral processing performance. From this technical point of view three textural features appear as the most significant for mineral liberation characterisation: grain size, grain boundary irregularity and the pattern of intergrowth type (Petruk, 2000; Ramdohr, 1980; Gaudin, 1939).

The characterisation of grain size determines how much grinding is required to achieve liberation. On the other hand, the nature of boundaries between intergrown minerals indicates whether mineral grains will break at the boundaries or not (Petruk, 1995),

\footnotetext{
* Corresponding author.

E-mail address: laura.perez.barnuevo@upm.es (L. Pérez-Barnuevo).
}

and therefore, the ease or difficulty of liberating the mineral of interest. Based on textural attributes a variety of mathematical models have been developed for predicting mineral liberations (Gaudin, 1939; Wiegel and Li, 1967; King, 1982; Gay, 2004). However, the application of these models is not widely spread and liberation is commonly estimated from laboratory testwork. Liberation estimations obtained experimentally are then represented by liberation curves, using the concept of cumulative liberation yield developed by Miller et al. (1982). These curves are usually based on liberation computed as weight proportion of the mineral of interest (MOI) in particles. However, when the ore presents complex texture, mainly when locking exists, liberation computed as surface exposed to reactants seems to be more appropriate (Lastra, 2002). In these cases, textural characterisation, and especially the characterisation of the intergrowth pattern, is essential to determine the response of mineral particles to separation processes and the possibility of increasing liberation by a regrinding stage. As an example, Fig. 1 shows the significance of the intergrowth type on mineral processing. This figure shows four chalcopyrite bearing particles in which chalcopyrite (bright phase) 

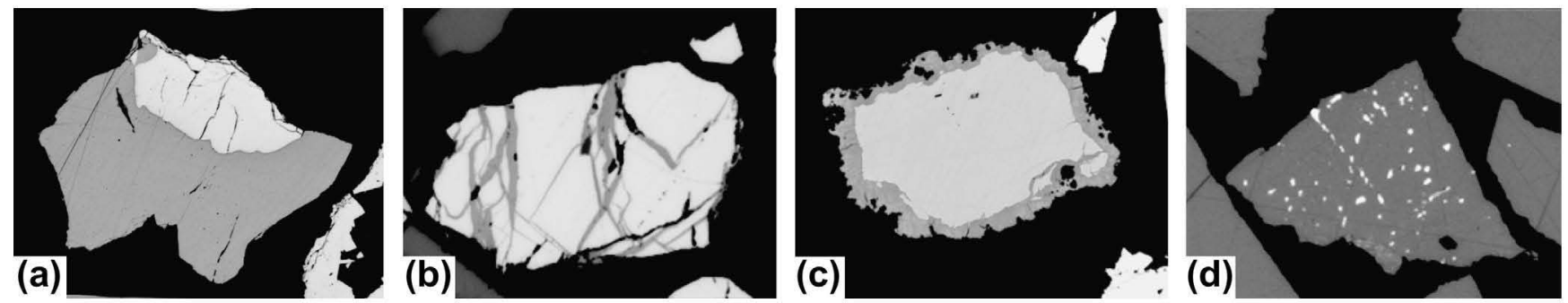

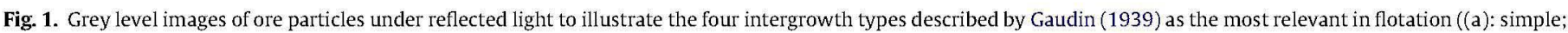
(b): stockwork; (c): coated; and (d): emulsion).

will behave in a completely different way during flotation and regrinding.

Several authors have developed different methods for textural analysis of unbroken ores (Amstutz and Giger, 1972; Steiner, 1975; Miller et al., 1982; Leigh, 2008). However, the characterisation of intergrowth patterns in mineral particles is usually descriptive and based on direct observations. The procedure lacks automation, thus involving major limitations in the quantitative characterisation of this textural feature, and its integration in a geometallurgical model. With the aim of automatically characterising the intergrowth type that one specific phase presents within mineral particles, a new methodology has been developed (PérezBarnuevo et al., 2012).

The main objective of this paper is to assess the ability of this new methodology to achieve a complete characterisation of the intergrowth types within mineral particles. This method has been tested by its application to the characterisation of chalcopyrite in the rougher concentrate of the Kansanshi copper ore. The variety of intergrowth patterns that this mineral presents in this sample, especially when it is associated with secondary copper sulphides, makes this sample particularly interesting to test the method, even though the separation of chalcopyrite and secondary copper sulphides is not a requirement for successful flotation in the particular case of the Kansanshi flotation circuit.

It should be noted that results achieved in this work are intended to show the potential of the method for general cases. Therefore, results are presented and discussed in order to evaluate and illustrate the ability of the methodology to provide quantitative information about textural attributes and not to assess the specific behaviour of chalcopyrite in the Kansanshi flotation circuit.

\section{Materials and methods}

To perform the characterisation of chalcopyrite in the selected sample, digital images have been acquired and classified with a Mineral Liberation Analyzer (MLA) system. After classification, more than 500 unliberated chalcopyrite bearing particles are analysed with the Textural Descriptors Methodology (Pérez-Barnuevo et al., 2012). Through this methodology a set of indices is computed and used to identify the intergrowth type by discriminant analysis. Apart from their expected discriminant power, these indices have been developed to characterise the minerallurgical behaviour of particles, so from now on they are referred to as minerallurgical indices.

\subsection{Rougher concentrate (RoCo) description}

The sample selected comes from the rougher concentrate of the sulphide ore flotation circuit in the Kansanshi copper-gold mine. This mine is located in the North Western Province of Zambia and benefits a mixed oxide/sulphide copper-gold vein deposit with very variable mineralization (Broughton et al., 2002).

Modal analysis performed with the Mineral Liberation Analyzer (MLA) determined that this sample is composed of chalcopyrite [Ccp] (54.2\%), pyrite [Py] (25.1\%), secondary copper sulphides [SsCu] (chalcocite, covellite, bornite and digenite, 11.1\%), gangue [Gg] (quartz, calcite, albite and dolomite $4.6 \%$ ), copper oxides [CuOx] (malachite and chrysocolla, 3.0\%), hematite [Hem] (1.7\%) and other minor components [Other] (0.3\%). Approximately $66 \%$ of the chalcopyrite is apparently liberated (i.e. in particles which appear completely composed by chalcopyrite in the 2D image, while composite chalcopyrite particles (i.e. unliberated chalcopyrite) usually present complex intergrowths (Fig. 2). In some of these particles, chalcopyrite is coated with a rim of secondary copper sulphides (Fig. 2a). In other cases, secondary copper sulphides occur as a network of fine veins cutting chalcopyrite (Fig. $2 b$ ), and sometimes chalcopyrite is coated and veined by secondary copper sulphides at the same time (Fig. 2c). Chalcopyrite in simple intergrowths is also present (Fig. $2 \mathrm{~d}$ ).

The first evidence of textural complexity in chalcopyrite is easily recognized analyzing Fig. 3 . In this figure, chalcopyrite liberation based on cumulative liberation yield has been computed. The upper curve represents the distribution of chalcopyrite by particle composition (liberation based on area proportion), while
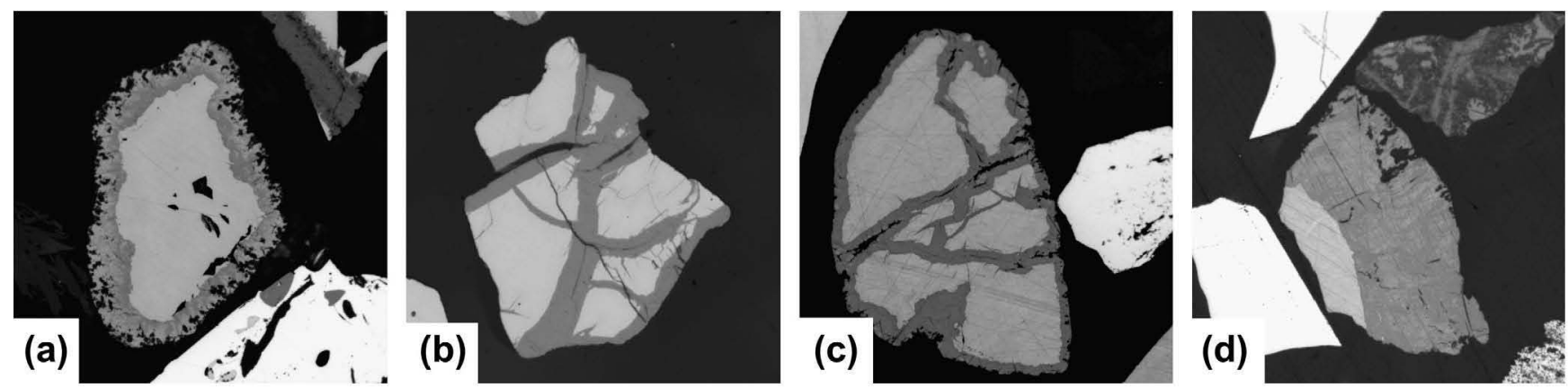

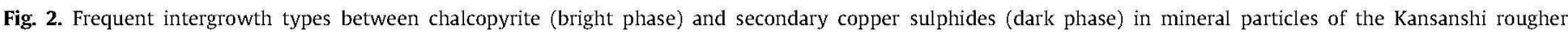
concentrate. 


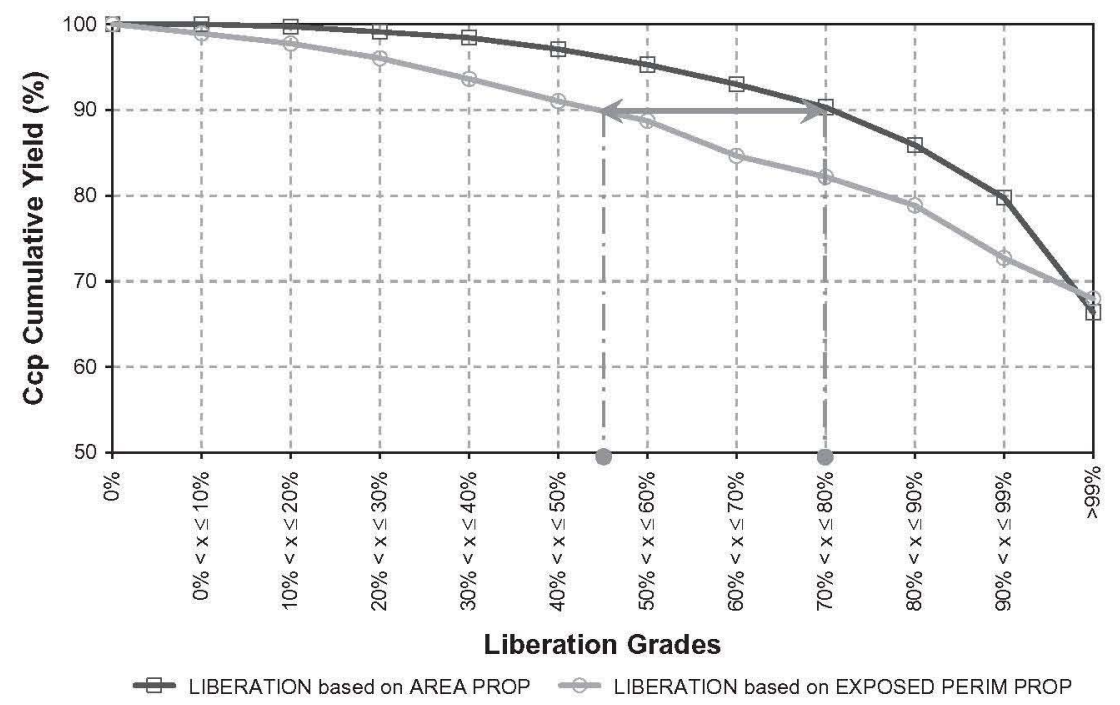

Fig. 3. Liberation curves for chalcopyrite in the rougher concentrate.

the lower one corresponds to the distribution of chalcopyrite by particle perimeter composition (liberation based on exposed perimeter proportion). An example of the difference in liberation data encountered in both curves is given by the evaluation of the cumulative liberation yield of $90 \%$ in both curves. In the upper curve (liberation based on area proportion) $90 \%$ of chalcopyrite is carried in particles with area fraction greater than $80 \%$ of chalcopyrite. In contrast, in the lower curve (liberation based on exposed perimeter proportion) $90 \%$ of chalcopyrite is in particles with perimeter proportion greater than $54 \%$. These differences observed between both curves indicate that the proportion of chalcopyrite exposed to reactants is lower than the amount of recoverable chalcopyrite indicated by the liberation curve based on weight proportion. Consequently, if liberation based on exposed perimeter is not provided along with liberation based on particle composition, the expected chalcopyrite recovery will be higher than the real one. In these cases, the characterisation of the intergrowth type can provide the information required to act on the ore so as to expose mineral surfaces and improve recoveries.

\subsection{Textural descriptors methodology}

Textural descriptors methodology has been developed to characterise the intergrowth type that one specific phase presents within mineral particles. This method is intended to be applied on digital images provided by optical or electron microscopy. After acquisition and classification, images are processed to select only unliberated particles bearing the MOI. Finally each particle is analysed with the linear intercepts method. This method is based on stereology, i.e. the science of the geometrical relationships between a structure that exists in three dimensions and the images of that structure that are fundamentally two-dimensional (Russ and Dehoff, 2000). The linear intercepts method is applied by superimposing a set of lines with different orientations on the particle. Along each test line the number of intersections between the line and each grain boundary is counted, identifying the type of boundary intercepted as a phase-to-phase contact or a phaseto-background contact (Pérez-Barnuevo et al., 2012). These counts are used by stereology to compute perimeters (Hyksova et al., 2012), and overall are used to compute the well-known stereological parameter $S_{V}$ or surface area per unit volume (Underwood, 1970). The computation of perimeters is especially useful to estimate the exposed perimeter proportion of the MOI in each particle (Fig. 4a), while the specific surface area has been traditionally used to estimate the intergrown surface between two minerals (Fig. 4b) (Amstutz and Giger, 1972; Miller et al., 1982; Steiner, 1975). Also, the length of the test line running through each phase in the particle is measured to compute linear grades, which is the proportion of the MOI per test line (Jones et al., 1978). If the total length of test line lies completely on the MOI, i.e. its linear grade is equal to 1 , the line is considered as liberated and the proportion of liberated test lines composed by the mineral of interest is called apparent linear liberation. In contrast, if the test line lies on two or more phases it is considered as an unliberated linear intercept (Schneider, 1995). The computation of linear grades for every test line enables the calculation of the linear grades distribution, which is considered a function of texture (King, 1983; Schneider, 1995; Jones et al., 1978).

\subsection{Minerallurgical indices}

Based on the computation of perimeters, specific surface area and linear grades, a set of indices (Table 1) has been developed. Each index provides valuable information to characterise mineralogical features of the MOI (represented by $\alpha$ ). Moreover, these indices are used to identify the intergrowth type by discriminant analysis. The discriminant power of indices in Table 1 has been tested on real mineral particles which present one specific intergrowth type. The test shows a total ratio of $95.5 \%$ correctly classified cases, using the Mahalanobis minimum distance as classification criteria (Pérez-Barnuevo et al., 2012).

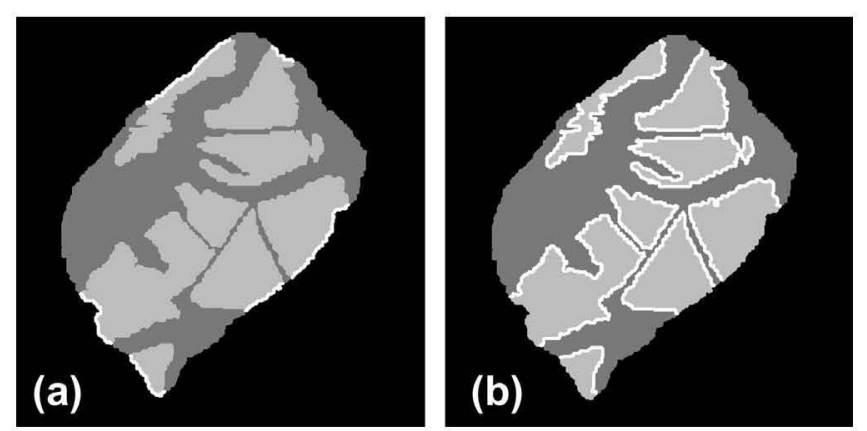

Fig. 4. highlighted in white: (a) exposed perimeter of the MOI and (b) intergrown surface between the MOI and the other minerals in the particle. 
Table 1

Minerallurgical indices.

\begin{tabular}{|c|c|c|}
\hline Index [range] & Definition & Significance \\
\hline \multicolumn{3}{|c|}{ Classical liberation indices } \\
\hline$A_{A}(\alpha)[0-1]$ & Volumetric proportion & Proportion of phase $\alpha$ in the particle \\
\hline$B_{B}(\alpha)[0-1]$ & Surface liberation & Proportion of phase $\alpha$ exposed at the surface of the particle \\
\hline \multicolumn{3}{|c|}{ Texture complexity index } \\
\hline$I_{T C}(\alpha \beta)[0-\infty]$ & Texture complexity Index & Grain boundary irregularity and texture complexity quantifier \\
\hline \multicolumn{3}{|c|}{ Linear grades distribution indices } \\
\hline$A_{L L}(\alpha)[0-1]$ & Apparent linear liberation & Proportion of $\alpha$ in the particle in liberated linear intercepts \\
\hline$L_{L}(\alpha)[0-1]$ & Average linear grade & Proportion of $\alpha$ in the particle in unliberated linear intercepts \\
\hline$L_{L 1}(\alpha)[0-1]$ & Linear grades distribution shape quantifier & The shape of the linear grades distribution is a function of texture \\
\hline \multicolumn{3}{|c|}{ Phase contact indices proposed by other authors } \\
\hline$I_{A-G}(\alpha \beta)[0-1]$ & Amstutz and giger intergrowth index & Surface quantifier of $\alpha \beta$ intergrowth \\
\hline$I_{J}(\alpha \beta)[0-1]$ & Jeulin coordination index & Probability of the $\alpha \beta$ contact in a multiphase system \\
\hline$I_{C G}(\alpha \beta)[0-1]$ & Gurland contiguity index & Proportion of $\alpha$ intergrown with $\beta$ \\
\hline
\end{tabular}

The first two indices, referred to as classical liberation indices, indicate the proportion of the MOI in the particle and the proportion of the MOI exposed to reactants respectively. In the second category there is one index that was developed to indicate the existence of texture complexity in the particle and to quantify grain boundary irregularity. Indices in the third group are based on the linear grades computation and were developed because of their expected discriminant power. In this work, the distribution of linear grades is based on the proportion of the MOI in linear grade classes, instead of on the number of linear intercepts. Based on this approach three indices have been developed: apparent linear liberation, computed as the number of pixels of $\alpha$ in liberated linear intercepts over the total number of pixels in the particle; Average linear liberation, calculated as the number pixels of $\alpha$ in unliberated linear intercepts over the total number of pixels in the particle; and a quantifier of the linear grades distribution shape. In the last group indices suggested by other authors (Amstutz and Giger, 1972; Jeulin, 1981; Gurland, 1958) are included after being modified to suit the special case of particle-by-particle analysis instead of analyzing a multiphase material aggregate. These indices quantify the degree of contact between phases within particles by means of different $S_{V}$ ratios.

\section{Results and discussion}

As shown in Fig. 1, the pattern of the intergrowth type plays an important role in the behaviour of ores during mineral processing. The presence of coatings on the surface of particles (Fig. 1c) may cause losses or dilution depending on whether the interest phase is the coated one or it is the one which forms the coating. The intergrowth known as chalcopyrite disease (Fig. 1d) has also a high impact on mineral processing. The finely dispersed blebs of chalcopyrite (usually smaller than $5 \mu \mathrm{m}$ ) are difficult or impossible to liberate, especially due to the commonly excessive cost of such a fine grinding. The presence of this intergrowth results in unavoidable copper losses in the flotation tails and appreciable copper reporting in the other concentrates (Craig and Vaughan, 1994). Another singular intergrowth pattern is the one shown in Fig. 1b. In this case, differences between the mechanical properties of the mineral in the matrix and the mineral forming the stockwork may lead to an excessive production of middlings and overgrinding during comminution.

Due to the fact that each intergrowth pattern requires a specific treatment, the quantitative distribution of the ore by intergrowth type seems to be an appropriate form to present the results. In this work, different approaches for the application of this distribution are analysed and complemented with quantitative information about each intergrowth type. In these charts an additional category (NC: not-classified) has been added to include the proportion of chalcopyrite in particles which do not fit any of the intergrowths shown in Fig. 2. These particles were classified with a Mahalanobis distance greater than 40 in the discriminant analysis. Prior to analyzing the final results, some comments are made on the minerallurgical significance of indices.

\subsection{Minerallurgical interpretation of indices}

Fig. 5 shows one of the images from the sample analysed. Fig. 5a is the classified image provided by MLA and Fig. 5b contains some of the unliberated chalcopyrite particles to be analysed with the
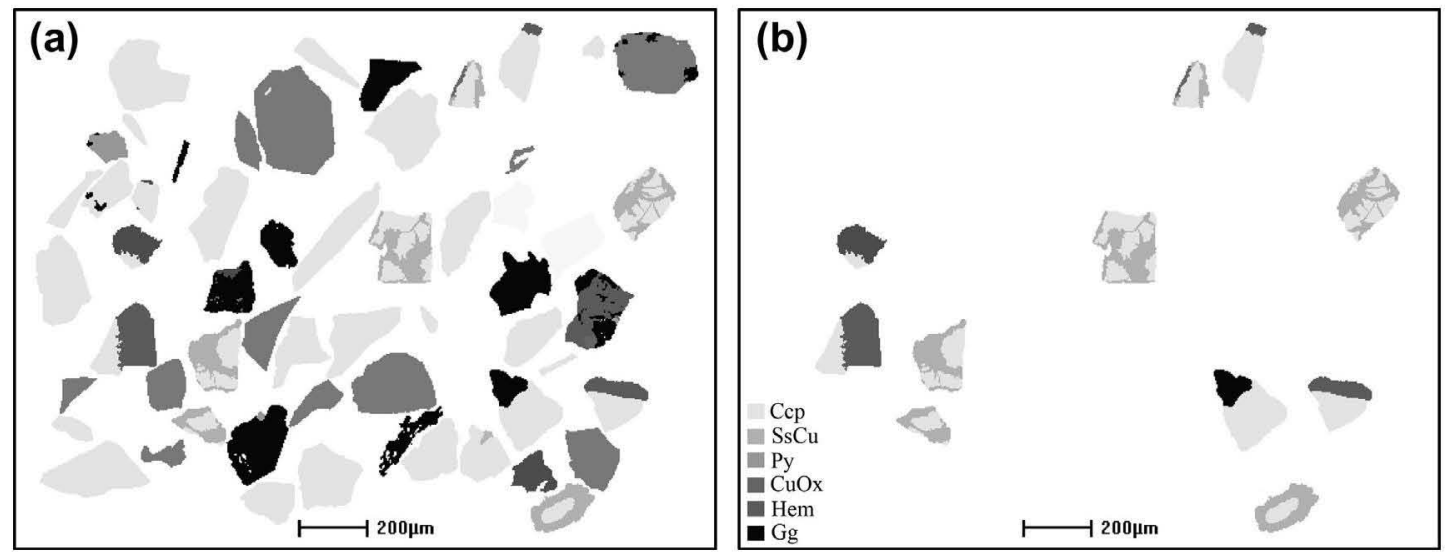

Fig. 5. Image of the rougher concentrate: (a) classified image provided by MLA; and (b) unliberated chalcopyrite particles to be analysed. 
textural descriptors methodology. Some of these have been computed because of their discriminant power (it is the case of the indices based on linear grades computation). However, there are other indices whose values give a direct indication of the presence or lack of some textural properties.

The two first indices from Table 2 provide important information as they quantify the fraction of chalcopyrite in the particle and the fraction of this mineral accessible to reactants respectively. With the values of these indices liberation curves based on cumulative liberation yields are computed (Fig. 3).

A very informative index is texture complexity index (ITC). This index quantifies the complexity of the texture in the particle, which is a key factor to determine the ease or difficulty of liberation. If texture is complex, liberation by detachment will be hardly achieved and regrinding will probably lead to middlings production. $I_{T C}$ is computed by means of a ratio between the real intergrown surface between two phases within a particle and the ideal minimum intergrown surface possible for that particle (Pérez-Barnuevo et al., 2012). For particles in which texture is complex (particles 5 and 11 in Table 2) this index takes high values (far from unity). In contrast, for particles showing simple intergrowth (particles 1, 2, 7, 8 and 10) this index is close to one. Moreover, once the intergrowth has been identified as simple, it has been observed that this index takes values closer to two when the grain boundary is irregular (compare $I_{T C}$ in particles 1 and 2 with particles 7, 8 and 10). Therefore, it also indicates the presence of grain boundary irregularity. According to $I_{T C}$ values, there is a factual relationship between this index and texture. However, further work has to be done in order to explore how to use this index to forecast mineral liberation.

The minerallurgical meaning of indices derived from the linear grades distribution $\left(A_{L L}, L_{L}\right.$ and $\left.L L_{1}\right)$ is not as evident as it is for the other indices. However, their discriminant power is high (PérezBarnuevo et al., 2012), thus the computation of these three indices is essential for the identification of the intergrowth type by discriminant analysis.

Table 2

Minerallurgical indices for chalcopyrite in unliberated particles in Fig. 5b.

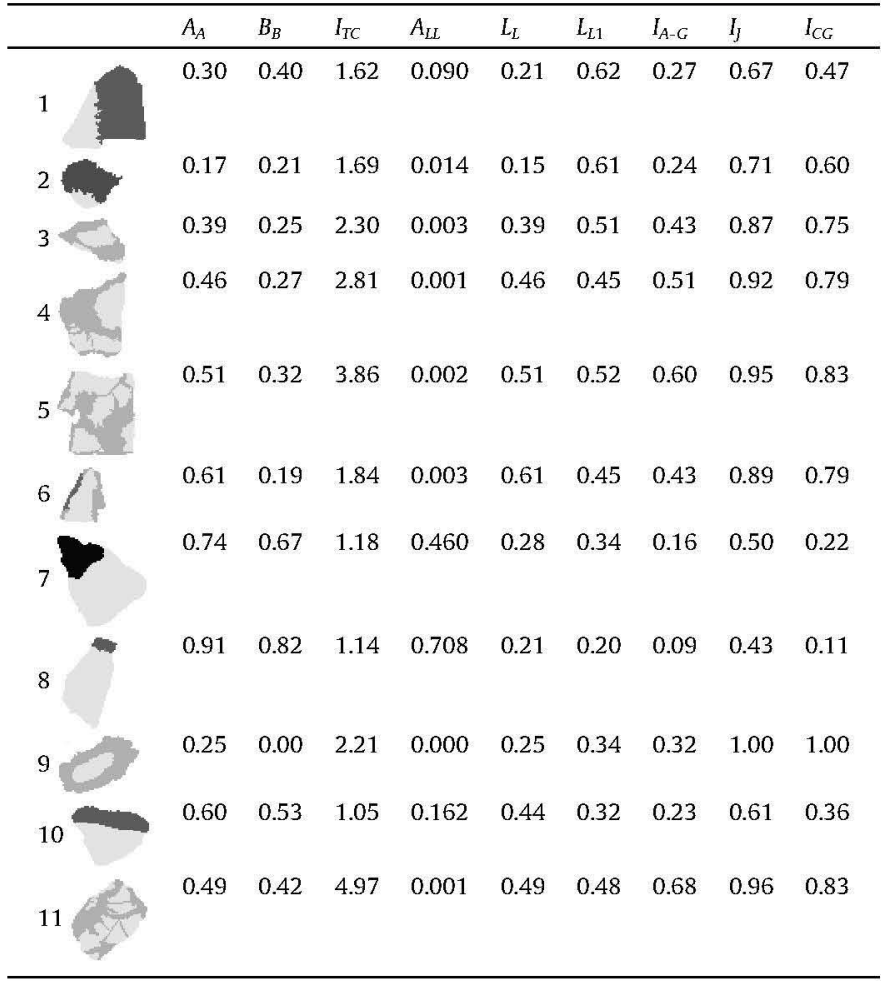

Index developed by Amstutz and Giger (1972), $I_{A G}$, indicates how much of each phase is intergrown with other phases in a multiphase material. The computation of this index indicates the efficiency of the separation process for a specific mineral association. Finally, indices proposed by Jeulin- $I_{J^{-}}-(1981)$ and Gurland $-I_{C G^{-}}$ (1958) are indicative of complete locking in particulate systems Both indices are equal to one when complete locking occurs (particle number 9 in Table 2 ).

\subsection{Distribution of chalcopyrite by intergrowth type}

Through a previous analysis of the sample carried out by optical microscopy, it has been observed that chalcopyrite in the rougher concentrate frequently presents one of the intergrowth types shown in Fig. 2. For that reason, the method has been applied to quantify the distribution of chalcopyrite with respect to intergrowth types (Fig. 6).

Along with the distribution of chalcopyrite by intergrowth type, the method gives additional data which provide metallurgists with valuable information to process the ore according to textural properties. As an example, Fig. 7 shows additional information provided by the method for particles in which chalcopyrite is coated by a rim or a semi-rim. In this case, grain size distribution for chalcopyrite inclusions and rim thickness has been quantified, along with the composition of the rim (e.g. $1.8 \%$ of chalcopyrite in the sample is coated by a rim composed of $\mathrm{SsCu} ; 0.1 \%$ of chalcopyrite is coated by a rim composed of $\mathrm{SsCu}$ and gangue; $0.4 \%$ of chalcopyrite is coated by $\mathrm{SsCu}$ and other minerals). In the same way, the $5.1 \%$ of chalcopyrite in the form of a matrix cut by stockwork can be analysed. For particles with this type of intergrowth, the composition of the stockwork and the grain size distribution of chalcopyrite and stockwork can be essential to determine the conditions of a regrinding stage.

\subsection{Distribution of chalcopyrite by intergrowth type and liberation grade}

Particularly interesting is the use of the intergrowth type characterisation to complement the information provided by the liberation curves. The distribution of the ore mineral by intergrowth type enables the characterisation of textural attributes for particles of a particular grade or in a range of grades. Approximately $9.4 \%$ of the chalcopyrite in the RoCo sample is in particles with a grade between $50 \%$ and $80 \%$ chalcopyrite. In Fig. 8 , the distribution of chalcopyrite by intergrowth type has been computed for particles of

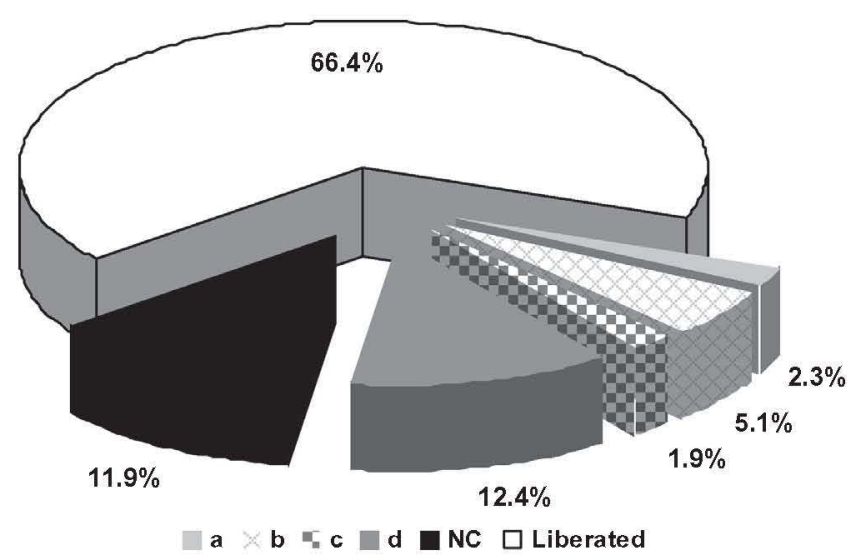

Fig. 6. Distribution of chalcopyrite by intergrowth type ((a): chalcopyrite coated by rim or semi-rim; (b): chalcopyrite cut by stockwork; (c): chalcopyrite cut by stockwork and coated by a rim; and (d): chalcopyrite in simple intergrowth; NC: chalcopyrite not-classified). 


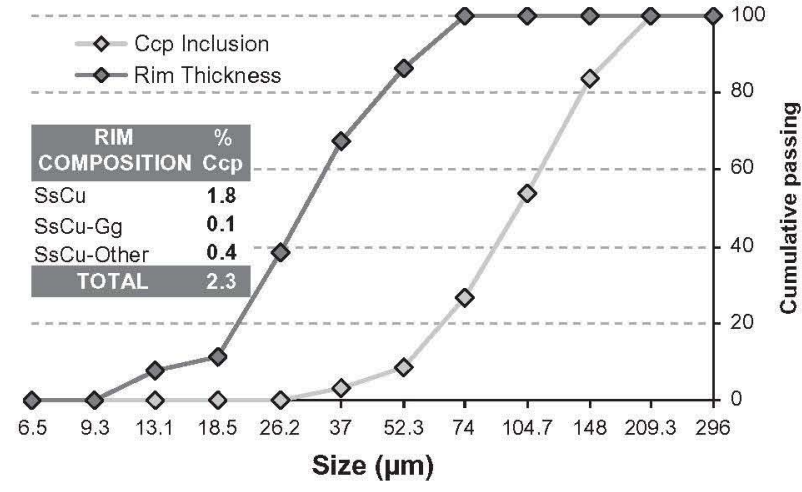

Fig. 7. Composition of the rim and size distribution for chalcopyrite inclusions and rim thickness in particles in which chalcopyrite is coated by a rim.

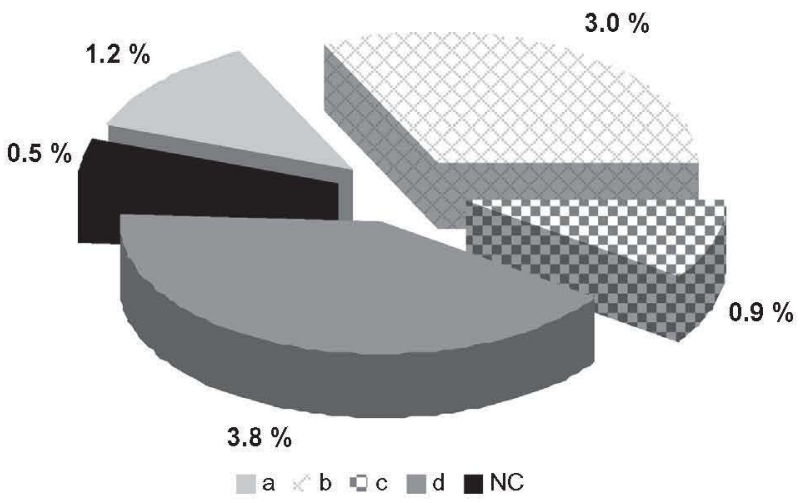

Fig. 8. Distribution of chalcopyrite by intergrowth type in the range of grades comprised between $50 \%$ and $80 \%$ (a: chalcopyrite coated by rim or semi-rim; b: chalcopyrite crossed by stockwork; (c): chalcopyrite crossed by stockwork and coated by a rim; and (d): chalcopyrite in simple intergrowth; NC: chalcopyrite notclassified).

grades in this range. This characterisation enables a more accurate and efficient definition of the treatment to be applied to a particular group of particles.

\subsection{Analysis of mineral association by intergrowth type}

Modal composition of particles provides the information to classify each particle as liberated, binary, ternary, etc. and to define the frequency of a particular mineral association. If this information is combined with the intergrowth type identification, it is possible to know the intergrowth type which usually presents any specific mineralogical association. For example, in the RoCo sample chalcopyrite is usually associated with secondary copper sulphides, and approximately $17.7 \%$ of chalcopyrite is in binary particles associated with secondary copper sulphides. Using this method, the distribution of this mineral association by intergrowth can be quantified (Fig. 9). In this case, the characterisation of this association is not relevant (because chalcopyrite and secondary copper sulphides are recovered in the same flotation stage). However, in other cases, this information can be important to know how to treat more efficiently a specific mineral association.

\section{Conclusions}

When ores present complex textures, mainly when a high degree of locking exists, the characterisation of the intergrowth type is essential to accomplish a more accurate description of the

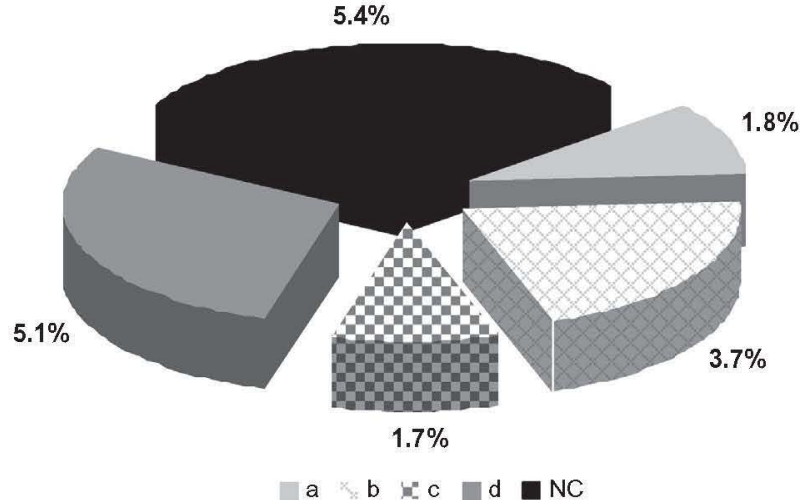

Fig. 9. Distribution of the chalcopyrite associated with secondary copper sulphides by intergrowth type ((a): chalcopyrite coated by rim or semi-rim; (b): chalcopyrite crossed by stockwork; (c): chalcopyrite crossed by stockwork and coated by a rim; and (d): chalcopyrite in simple intergrowth; NC: chalcopyrite not-classified).

liberation characteristics of the ore. Some authors (Amstutz and Giger, 1972; Steiner, 1975; Miller et al., 1982; Leigh, 2008) have attempted to quantitatively characterise the intergrowth between minerals in unbroken ores. However, the characterisation of the intergrowth patterns within mineral particles is commonly performed by qualitative observations, despite the fact that the quantitative characterisation of this textural feature is essential to achieve a better understanding of the mineral particles' behaviour during concentration processes. In this work, the ability of a new methodology to provide a complete and automated characterisation of the intergrowth type within mineral particles has been tested. For this purpose, chalcopyrite particles from the rougher concentrate of the Kansanshi copper mine have been analysed by the computation of a set of minerallurgical indices. For these particular ores there is no need to separate chalcopyrite and secondary copper sulphides, but this sample has been selected for illustration of the methodology and its performance, as it presents an interesting variety of intergrowth patterns. Therefore, results are discussed with regard to a general application of the methodology for any type of ore, and not for the particular Kansanshi flotation circuit.

The results obtained show that this new methodology provides a vast amount of mineralogical information. This information is not available by current methods, but it enables a more accurate and efficient definition of mineral processing. Results have been presented showing the distribution of chalcopyrite by intergrowth type. Different examples of the application of this distribution have been given to show the versatility of the method. Moreover, the method provides additional information to characterise the main textural features of each intergrowth type, e.g. rim composition and thickness.

Along with the information provided by the joint use of the minerallurgical indices, in this work the individual contribution of each index has been assessed. Especially useful is the $I_{T C}$, which indicates the complexity of the texture in the particle. If the ore has a high $I_{T C}$ (i.e. if it presents complex texture) a high degree of liberation will be more difficult to achieve than for another ore whose $I_{T C}$ is close to one. Further work should establish the potential use of the $I_{T C}$ not only as an indicator of the expected degree of liberation, but also as a classifier of behaviour with regard to recovery processes.

\section{Acknowledgements}

This research was supported by a FPI Grant from Universidad Politécnica de Madrid and by Project CAMEVA (CGL2006-13688C02-01), funded by the Spanish Research Authority (Ministerio de Educación y Ciencia, Madrid). The authors would like to acknowledge the Canadian Mining \& Minerals Sciencies Laborato- 
ries (CANMET) and especially Dr. Rolando Lastra, for his collaboration in the use of MLA for the acquisition of the digital images used in this work. The authors would also like to thank First Quantum for providing the sample for this study. The contribution of the editor of the review, and two anonymous reviewers to the improvement of the original text is gratefully acknowledged.

\section{References}

Amstutz, G.C., Giger, H., 1972. Stereological methods applied to mineralogy, petrology, mineral deposits and ceramics. J. Microsci. 25 (1), 145-164.

Bonici, N., Hunt, J.A., Walters, S.G., Berry, R. Collet, D., 2008. Relating textura attributes to mineral processing - developing a more effective approach for the Cadia east $\mathrm{Cu}-\mathrm{Au}$ porphyry deposit. In: 9 th International Congress for Applied Mineralogy ICAM, 8-10 September, Brisbane, Queensland.

Broughton, D.W., Hitzman, M.W., Stephens, A.J., 2002. Exploration History and Geology of the Kansanshi $\mathrm{Cu}(-\mathrm{Au})$ Deposit, Zambia. Society of Economic Geologists, pp. 141-153 (Special publication 9).

Craig, J.R., Vaughan, D.J., 1994. Ore Microscopy and Ore Petrography, second ed. John Wiley and sons, Inc., New York - United States of America.

Gaudin, A.M., 1939. Principles of Mineral Dressing. McGraw-Hill, New York.

Gay, S.l., 2004. Simple texture-based liberation modelling of ores. Miner. Eng. 17, 1209-1261.

Gurland, J., 1958. The measurement of grain contiguity in two-phase alloys. Trans. Am. Inst. Mining Met. Eng. 212, 452.

Hyksova, M., Kalousova, A., Saxl, I., 2012. Early history of geometric probability and stereology. Image Anal. Stereol. 31, 1-16.

Jeulin, D., 1981. Mathematical morphology and multiphase materials. In: Proc. 3rd Eur. Symp. on Stereology, Ljubljana, pp. 265-286.
Jones, M.P., Coleman, R., Horton, R., 1978. The assessment of composite particles from linear measurements. In: Proc. 2nd Eur. Symp. on Quantitative Analysis of Microstructures, Caen, p. 182

King, R.P., 1982. The Prediction of Mineral Liberation from Mineralogical Texture XIVth International Mineral Processing Congress, Toronto.

King, R.P., 1983. Stereological methods for the prediction and measurement of mineral liberation. In: De Villiers, Cawthorn (Eds.), pp. 443-447.

Lastra, R., 2002. A comparison of liberation determinations by particle are percentage and exposed particle perimeter percentage in a flotation concentrator. J. Miner. Mater. Characterisation Eng. 1 (1), 31-37.

Leigh, G.M., 2008. Automatic ore texture analysis for process mineralogy. In: 9th International Congress for Applied Mineralogy, Brisbane, OLD 8-10 September.

Miller, P.R., Reid, A.F., Zuiderwyk, M.A., 1982. QEM*SEM Image Analysis in the Determination of Modal Assays, Mineral Associations and Mineral Liberaton. XIVth International Mineral Processing Congress, Toronto.

Pérez-Barnuevo, L., Pirard, E., Castroviejo, R., 2012. Textural descriptors for multiphasic ore particles. Image Anal. Stereol. 2012 (31), 175-184.

Petruk, W., 2000. Applied Mineralogy in the Mining Industry, first ed. Elsevier Amsterdam, The Nertherlands, 268.

Petruk, W., 1995. Some Relationships Between Mineral Textures and Extractive Metallurgy. Process Mineralogy XIII. The Minerals, Metals and Materials Society.

Ramdohr, P., 1980. The Ore Minerals and their Intergrowths, second ed. Pergamon Press, Oxford

Russ, J.C., Dehoff, R.T., 2000. Practical Stereology. Plenum Press, New York.

Schneider, C.L., 1995. Measurement and Calculation of Liberation in Continuous Milling Circuits. Ph.D. dissertation. University of Utah.

Steiner, H.J., 1975. Liberation Kinetics in Grinding Operations. Proc. XIth Int. Min. Proc. Cong. Caligiari, pp. 35-58.

Underwood, E.E., 1970. Quantitative Stereology. Addison Wesley, Reading Massachusetts.

Wiegel, R.L., Li, K., 1967. A random model for mineral liberation by size reduction. Trans. SME-AIME 238, 179 